\title{
The Relationship between Vitamin D Status and Visceral Fat Accumulation in Males with Type 2 Diabetes
}

\author{
Bowei LIU, Dongmei FAN and Fuzai YIN* \\ Department of Endocrinology, The First Hospital of Qinhuangdao, No. 258 Wenhua Road, \\ Qinhuangdao, 066000, Hebei Province, China
}

(Received February 24, 2020)

\begin{abstract}
Summary Vitamin D deficiency may play an important role in obesity. The aim of the study was to explore the relationship between vitamin D status and visceral fat accumulation in males with type 2 diabetes. A cross-sectional study was conducted on 128 adult males with type 2 diabetes in Qinhuangdao. The nutritional status of vitamin D was assessed by circulating levels of $25(\mathrm{OH}) \mathrm{D}$, vitamin D deficiency $<30 \mathrm{nmol} / \mathrm{L}$, vitamin $\mathrm{D}$ insufficiency $30-50 \mathrm{nmol} / \mathrm{L}$ and vitamin D sufficiency $>50 \mathrm{nmol} / \mathrm{L}$. Accumulation of visceral fat was defined as visceral fat area $\geqslant 100 \mathrm{~cm}^{2}$. The prevalence of visceral fat accumulation was $35.9 \%$. The prevalence of visceral fat accumulation was $14.6 \%, 45.1 \%$ and $50.0 \%$ in type 2 diabetes with vitamin D sufficiency, vitamin D insufficiency and vitamin D deficiency, respectively. In multiple logistic regression analysis, subjects with vitamin D insufficiency $[\mathrm{OR}=4.255, p=0.012]$ and vitamin $\mathrm{D}$ deficiency $[\mathrm{OR}=6.122, p=0.022]$ were more likely to have visceral fat accumulation compared with subjects with vitamin D sufficiency. Visceral fat accumulation linked to the cluster of cardiometabolic risk factor in males with type 2 diabetes. There was a significant correlation between vitamin D status and visceral fat accumulation in males with type 2 diabetes.
\end{abstract}

Key Words obesity, vitamin D deficiency, prevalence, cardiometabolic risk factor, diabetes

Type 2 diabetes is a serious threat to human health in China. Obesity plays an important role in the development and progression of type 2 diabetes. Obesity increased the risk of type 2 diabetes by aggravated insulin resistance $(1,2)$. Obesity also increased the risk of chronic complications of type 2 diabetes $(3,4)$. The fat distribution influences the outcomes of obesity. Excess visceral adipose are associated with vascular endothelial function, atherosclerosis and cardiovascular disease in type 2 diabetes (5-7).

Vitamin D deficiency is widespread around the world $(8,9)$. The classical role of vitamin $\mathrm{D}$ is about bone health. Vitamin D also has potential role in the prevention of nonskeletal disorders such as auto-immune disease, cancer, mental health problems and cardiovascular disease (10-13).

Vitamin D deficiency may play an important role in obesity. In a meta-analysis, vitamin D deficiency is associated with an increased level of body mass index (BMI) in both diabetic and non-diabetic subjects (14). Vitamin $\mathrm{D}$ deficiency was positively associated with both general and abdominal obesity (15). Abdominal visceral adipose tissue (VAT) are inversely associated with serum 25-hydroxyvitamin D [25(OH)D] concentrations in the general adult population from China, Germany and Denmark $(16,17)$. Hao et al. also found that $25(\mathrm{OH}) \mathrm{D}$ were inversely associated with visceral fat area (VFA) in Chinese males with normal glucose tolerance (18).

\footnotetext{
*To whom correspondence should be addressed.

E-mail: yinfuzai62@163.com
}

In type 2 diabetes, vitamin $\mathrm{D}$ deficiency is also associated with obesity $(19,20)$. However, obesity was evaluated by BMI, not VFA, in these studies. The aim of our study was to determine the relationship between vitamin D status and visceral fat accumulation in males with type 2 diabetes.

\section{METHODS}

Subjects. After obtaining informed consent from males with type 2 diabetes a cross-sectional study was conducted. All subjects were adult males with a diagnosis of type 2 diabetes (21). The exclusion criteria included the following: 1 ) subjects with type 1 diabetes, 2) subjects with clinical evidence of other endocrinopathy, 3) subjects were taking vitamin D, 4) subjects with renal dysfunction (estimate glomerular filtration rate (eGFR) less than $60 \mathrm{~mL} \times \mathrm{min}^{-1} \times 1.73 \mathrm{~m}^{-2}$ ) or hepatic dysfunction (alanine aminotransferase (ALT) $>100$ U/L), 5) subjects with acute and chronic inflammation. This study was approved by the ethics committee of the First Hospital of Qinhuangdao (No. 2015C061). All subjects provided written informed consent before study initiation.

Measurements. Anthropometric measurements, including height, weight and waist circumference (WC) were obtained. WC was accurately measured at the level of midway between the lowest rib and the top of the iliac crest. Blood pressure was measured with a mercury sphygmomanometer while the subjects were seated after $10 \mathrm{~min}$ of rest. Sociodemographic variables were collected and included: age, duration of diabetes, family 
Table 1. Characteristics of adult males with type 2 diabetes.

\begin{tabular}{|c|c|c|c|c|}
\hline Variables & $\begin{array}{l}\mathrm{VFA}<100 \mathrm{~cm}^{2} \\
\quad(n=82)\end{array}$ & $\begin{array}{c}\mathrm{VFA} \geqslant 100 \mathrm{~cm}^{2} \\
\quad(n=46)\end{array}$ & $t$ or $\chi^{2}$ & $p$ \\
\hline Age (y) & $50.9 \pm 11.5$ & $47.5 \pm 13.9$ & 1.474 & 0.143 \\
\hline Duration of diabetes (y) & $6.5 \pm 5.8$ & $5.2 \pm 5.1$ & 1.283 & 0.202 \\
\hline $\mathrm{FHD}[n(\%)]$ & $11(13.4)$ & $5(10.9)$ & 0.175 & 0.676 \\
\hline Hypertension [n (\%)] & $32(39.0)$ & $21(45.7)$ & 0.534 & 0.465 \\
\hline Smoking $[n(\%)]$ & $41(50.0)$ & $26(56.5)$ & 0.502 & 0.478 \\
\hline Drinking $[n(\%)]$ & $47(57.3)$ & $25(54.3)$ & 0.106 & 0.745 \\
\hline BMI $\left(\mathrm{kg} / \mathrm{m}^{2}\right)$ & $25.5 \pm 2.4$ & $29.4 \pm 2.9$ & 7.496 & $<0.001$ \\
\hline $\mathrm{WC}(\mathrm{cm})$ & $88.7 \pm 7.1$ & $102.5 \pm 7.8$ & 10.096 & $<0.001$ \\
\hline SBP (mmHg) & $125.3 \pm 12.6$ & $124.1 \pm 9.0$ & 0.607 & 0.545 \\
\hline DBP (mmHg) & $81.8 \pm 7.9$ & $82.0 \pm 6.7$ & 0.188 & 0.851 \\
\hline FPG (mmol/L) & $9.80 \pm 3.73$ & $11.07 \pm 3.98$ & 1.788 & 0.076 \\
\hline HbA1c (\%) & $8.5 \pm 1.9$ & $8.9 \pm 1.9$ & 1.083 & 0.281 \\
\hline $\mathrm{TG}(\mathrm{mmol} / \mathrm{L})$ & $2.13 \pm 1.71$ & $3.53 \pm 4.01$ & 2.255 & 0.028 \\
\hline HDL-C (mmol/L) & $1.09 \pm 0.33$ & $0.93 \pm 0.24$ & 2.848 & 0.005 \\
\hline ALT (U/L) & $26.4 \pm 16.5$ & $30.1 \pm 18.6$ & 1.138 & 0.257 \\
\hline $\mathrm{Cr}(\mu \mathrm{mol} / \mathrm{L})$ & $62.9 \pm 12.1$ & $62.1 \pm 14.0$ & 0.358 & 0.721 \\
\hline $\mathrm{eGFR}\left(\mathrm{mL} \times \min ^{-1} \times 1.73 \mathrm{~m}^{-2}\right)$ & $140.7 \pm 41.5$ & $147.5 \pm 47.4$ & 0.837 & 0.404 \\
\hline 25(OH)D (nmol/L) & $50.1 \pm 18.8$ & $40.8 \pm 12.9$ & 3.290 & 0.001 \\
\hline
\end{tabular}

VFA: visceral fat area; FHD: family history of diabetes; BMI: body mass index; WC: waist circumference; SBP: systolic blood pressure; DBP: diastolic blood pressure; FPG: fasting plasma glucose; HbA1c: glycosylated hemoglobin A1c; TG: triglyceride; HDL-C: high-density lipoprotein cholesterol; ALT: alanine aminotransferase; Cr: creatinine; eGFR: estimate glomerular filtration rate; 25(OH)D: 25-hydroxyvitamin D.

history of diabetes (FHD, defined as mothers, fathers, offsprings or siblings with type 2 diabetes), hypertension (subjects with history of hypertension or systolic blood pressure (SBP) and/or diastolic blood pressure (DBP) $\geqslant 140 / 90 \mathrm{mmHg}$ for three screenings), smoking and drinking status.

After a 10-h overnight fast, blood samples were collected from an antecubital vein into heparinised tubes. Fasting plasma glucose (FPG) concentration was measured using the glucose oxidase method, and serum lipid levels, as well as renal and hepatic function, were measured using enzymatic assays with an autoanalyzer (Hitachi, Tokyo, Japan). Glycosylated hemoglobin A1c (HbA1c) was measured by highperformance liquid chromatography (HPLC). Serum 25-hydroxyvitamin D $[25(\mathrm{OH}) \mathrm{D}]$ was measured using enzyme linked immunosorbent assay (ELISA) kits produced by UK IDS Company. $\mathrm{eGFR}=175 \times$ creatinine $(\mathrm{Cr}, \mathrm{mg} / \mathrm{dL})^{-1.234} \times$ age $(\mathrm{y})^{-0.179}(22)$.

Definition of metabolic syndrome. Metabolic syndrome (MetS) was defined using the definition of Chinese Diabetes Society. Participants had to meet any 3 or more of the following 5 factors: 1) abdominal obesity: $W C \geqslant 90 \mathrm{~cm}, 2)$ abnormal glucose metabolism: FPG $\geqslant 6.1 \mathrm{mmol} / \mathrm{L}$ or 2 -h plasma glucose levels $\geqslant 7.8$ $\mathrm{mmol} / \mathrm{L}$ after a 75 -g oral glucose tolerance test (OGTT) or have been diagnosed with diabetes, 3) elevated blood pressure: blood pressure $\geqslant 130 / 85 \mathrm{mmHg}$ or have been diagnosed with hypertension, 4) high triglyceride (TG): $\mathrm{TG} \geqslant 1.7 \mathrm{mmol} / \mathrm{L}, 5$ ) low high density lipoprotein cholesterol (HDL-C): HDL-C $<1.04 \mathrm{mmol} / \mathrm{L}$ (23).

Vitamin $D$ status. The nutritional status of vitamin
D was assessed by circulating levels of $25(\mathrm{OH}) \mathrm{D}$, vitamin D deficiency $<30 \mathrm{nmol} / \mathrm{L}$, vitamin D insufficiency $30-50 \mathrm{nmol} / \mathrm{L}$ and vitamin D sufficiency $>50 \mathrm{nmol} / \mathrm{L}$ (24).

VFA estimation by bioelectrical impedance analysis (BIA). In this study, VFA was measured by the InBody S10 (Biospace Co, Ltd, Seoul, Korea) as an indicator of visceral fat accumulation. The measurements were performed with the subjects in sitting position. Measurements were taken using the 4-electrode 8-point touch electrode method by wiping the areas where the 8 electrodes would be attached (one each on thumb and middle fingers on both hands and one each on both ankles) with electrolyte tissue and connecting the holder electrode. Visceral fat accumulation was defined as $\mathrm{VFA} \geqslant 100 \mathrm{~cm}^{2}(25)$.

Statistical analyses. All analyses were performed using the SPSS 11.5 statistical software (SPSS 11.5 for Windows; SPSS, Inc., Chicago, IL). Numerical variables were reported as mean \pm standard deviation. Comparisons were conducted between groups using the $t$ test. Comparison of prevalence data was performed by $\chi^{2}$ analysis. Multiple logistic regression models were used for modeling relationships between vitamin D status and visceral fat accumulation in males with type 2 diabetes. Computed tomography (CT) is golden methods for evaluating visceral adipose tissue. The correlation between visceral fat area measured by InBody S10 and by CT weakened in males with BMI $\geqslant 30 \mathrm{~kg} / \mathrm{m}^{2}(26)$. We excluded subjects with BMI $\geqslant 30 \mathrm{~kg} / \mathrm{m}^{2}$ and analyzed again. $p<0.05$ was considered statistically significant. 
Table 2. Prevalence of metabolic syndrome in type 2 diabetes patients with different levels of visceral fat area.

\begin{tabular}{|c|c|c|c|c|}
\hline Components & $\begin{array}{c}\mathrm{VFA}<100 \mathrm{~cm}^{2} \\
\quad(n=82)\end{array}$ & $\begin{array}{c}\mathrm{VFA} \geq 100 \mathrm{~cm}^{2} \\
\quad(n=46)\end{array}$ & $x^{2}$ & $p$ \\
\hline Abdominal obesity $[n(\%)]$ & $41(50.0)$ & $44(95.7)$ & 27.531 & $<0.001$ \\
\hline Elevated blood pressure $[n(\%)]$ & $42(51.2)$ & $26(56.5)$ & 0.333 & 0.564 \\
\hline High TG $[n(\%)]$ & $36(43.9)$ & $29(63.0)$ & 4.320 & 0.038 \\
\hline Low HDL-C $[n(\%)]$ & $37(45.1)$ & $36(78.3)$ & 13.206 & $<0.001$ \\
\hline Metabolic syndrome $[n(\%)]$ & $47(57.3)$ & $44(95.7)$ & 21.073 & $<0.001$ \\
\hline
\end{tabular}

VFA: visceral fat area; TG: triglyceride; HDL-C: high-density lipoprotein cholesterol.

Table 3. Prevalence of visceral fat accumulation across vitamin D status.

\begin{tabular}{|c|c|c|c|c|c|}
\hline \multirow{2}{*}{ Vitamin D status } & \multirow{2}{*}{$n(\%)$} & \multicolumn{2}{|l|}{ Model 1} & \multicolumn{2}{|l|}{ Model 2} \\
\hline & & OR $(95 \% \mathrm{CI})$ & $p$ & OR $(95 \% \mathrm{CI})$ & $p$ \\
\hline Sufficiency $(n=41)$ & $6(14.6)$ & 1 & & 1 & \\
\hline Insufficiency $(n=71)$ & $32(45.1)$ & $4.786(1.789-12.806)$ & 0.002 & $4.255(1.372-13.197)$ & 0.012 \\
\hline Deficiency $(n=16)$ & $8(50.0)$ & $5.833(1.577-21.572)$ & 0.008 & $6.122(1.298-28.881)$ & 0.022 \\
\hline
\end{tabular}

Table 4. Prevalence of visceral fat accumulation across vitamin D status in subjects with BMI $<30 \mathrm{~kg} / \mathrm{m}^{2}$.

\begin{tabular}{|c|c|c|c|c|c|}
\hline \multirow{2}{*}{ Vitamin D status } & \multirow{2}{*}{$n(\%)$} & \multicolumn{2}{|l|}{ Model 1} & \multicolumn{2}{|l|}{ Model 2} \\
\hline & & OR $(95 \%$ CI $)$ & $p$ & OR $(95 \%$ CI $)$ & $p$ \\
\hline Sufficiency $(n=41)$ & $6(14.6)$ & 1 & & 1 & \\
\hline Insufficiency $(n=53)$ & $16(30.2)$ & $2.523(0.886-7.179)$ & 0.083 & $3.292(0.902-12.021)$ & 0.071 \\
\hline Deficiency $(n=13)$ & $5(38.5)$ & $3.646(0.887-14.988)$ & 0.073 & $8.301(1.195-57.643)$ & 0.032 \\
\hline
\end{tabular}

Model 1: univariate logistic regression analysis. Model 2: multiple logistic regression analysis, visceral fat accumulation was considered as the dependent variables in a multiple logistic regression analysis with age, duration of diabetes, FHD, smoking, drinking, HbA1c, ALT, eGFR, metabolic syndrome and vitamin D status as independent variables. BMI: body mass index; OR: odds ratio; CI: confidence interval; FHD: family history of diabetes; HbA1c: glycosylated hemoglobin A1c; ALT: alanine aminotransferase; eGFR: estimate glomerular filtration rate.

\section{RESULTS}

This study enrolled 128 males with type 2 diabetes, age $49.7 \pm 12.5 \mathrm{y}$, duration of diabetes $6.0 \pm 5.6 \mathrm{y}$. Among these subjects, 46 males (35.9\%) were characterized by the accumulation of visceral fat. The age, history of diabetes, FHD, smoking and drinking were similar between patients with $\mathrm{VFA}<100 \mathrm{~cm}^{2}$ and $\mathrm{VFA} \geqslant 100 \mathrm{~cm}^{2}(p>0.05)$. The levels of BMI, WC and TG were all significantly higher in patients with $V F A \geqslant 100 \mathrm{~cm}^{2}$ than in patients with $V F A<100 \mathrm{~cm}^{2}$ $(p<0.05)$. The levels of HDL-C and 25(OH)D were all significantly lower in patients with $\mathrm{VFA} \geqslant 100 \mathrm{~cm}^{2}$ than in patients with VFA $<100 \mathrm{~cm}^{2}(p<0.05)$. The SBP, DBP, FPG and $\mathrm{HbA1c}$ were similar between patients with VFA $<100 \mathrm{~cm}^{2}$ and VFA $\geqslant 100 \mathrm{~cm}^{2}(p>0.05)$ (Table 1).

Except elevated blood pressure, the prevalences of abdominal obesity, high TG, low HDL-C and MetS were all significantly higher in patients with VFA $\geqslant 100 \mathrm{~cm}^{2}$ than in patients with VFA $<100 \mathrm{~cm}^{2}(p<0.05)$ (Table 2).

Among these subjects, $55.4 \%$ were characterized by the vitamin D insufficiency and $12.5 \%$ were characterized by the vitamin D deficiency. Multivariate-adjusted odds ratios (ORs) [and 95\% confidence intervals (CIs)] for visceral fat accumulation across different vitamin D status are shown in Table 3. The prevalence of visceral fat accumulation was $14.6 \%, 45.1 \%$ and $50.0 \%$ in type 2 diabetes with vitamin D sufficiency, vitamin D insufficiency and vitamin D deficiency, respectively. When visceral fat accumulation was considered as the dependent variables in a multiple logistic regression analysis with age, duration of diabetes, FHD, smoking, drinking, HbA1c, ALT, eGFR, metabolic syndrome and vitamin D 
status as independent variables, subjects with vitamin D insufficiency $[\mathrm{OR}=4.255, p=0.012]$ and vitamin $\mathrm{D}$ deficiency $[\mathrm{OR}=6.122, p=0.022]$ were more likely to have visceral fat accumulation compared with subjects with vitamin D sufficiency. After subjects with BMI $\geqslant 30 \mathrm{~kg} / \mathrm{m}^{2}$ were excluded, subjects with vitamin D insufficiency $[\mathrm{OR}=2.523, p=0.083]$ and vitamin $\mathrm{D}$ deficiency $[\mathrm{OR}=3.646, p=0.073]$ were still more likely to have visceral fat accumulation compared with subjects with vitamin D sufficiency (Table 4). This difference was not statistically significant.

\section{DISCUSSION}

More than a third of males with type 2 diabetes have visceral fat accumulation. MetS were very common in type 2 diabetes (27). However, the prevalence of MetS increased further, nearly $100 \%$, in males with visceral fat accumulation. When males present with these conditions together, the chances for MetS is greater than type 2 diabetes presenting alone.

In the Framingham Heart Study, the prevalence of MetS increased linearly across increasing VAT quartiles in males with normal-weight, overweight and obesity (28). In Chinese population, visceral fat was also a risk factor for MetS in males (29). Males with visceral fat obesity have higher risk of MetS even though with normal WC (30). Cohort study found that increased visceral fat promote the occurrence of metabolic abnormalities, especially abnormal lipid metabolism (31, 32). Consistent with previous research, dyslipidemia was worse in type 2 diabetes males co-exist with visceral fat accumulation.

The pattern of fat deposition exists gender differences. Males are more likely to deposit in the visceral fat (33). Visceral fat is mainly composed of mesenteric and omental fat and retroperitoneal adipose tissue (34). Mesenteric and omental fat are drained to the portal vein. Pro-inflammatory factors and free fatty acids from these depots are drained directly to the liver and eventually lead to hepatic insulin resistance and metabolic abnormalities (35). Epidemiologic studies also confirmed that VAT remains more strongly associated with MetS compared with subcutaneous adipose tissue $(28$, 36).

Vitamin D status is strongly associated with visceral adiposity in nondiabetic individuals (37). In our study, we found that vitamin D insufficiency and deficiency was also correlated with visceral fat accumulation in males with type 2 diabetes. The mechanism of vitamin $\mathrm{D}$ on fat metabolism is not very clear. In vitro experiments, 1,25-dihydroxyvitamin D3 restrains adipogenesis through suppressing the expression of CCAAT-enhancer-binding protein, peroxisome proliferator-activated receptor-gamma, involved in adipocyte differentiation (38). Preadipocytes have important role in the homeostasis of adipose tissue. Recent research found that 1,25-dihydroxyvitamin D3 modulate vitamin D receptor expression and cell cycle in preadipocytes (39).

The results of vitamin D supplementation on visceral fat accumulation were disagreement. In 2017, a sys- tematic review evaluated the effect of vitamin D supplementation on non-skeletal disorders. Vitamin D supplementation had no significant effect on markers of adiposity. In this study, adiposity was evaluated by BMI and weight (40). Several clinical trials verified that vitamin D with or without calcium supplementation contributes to a beneficial reduction of VAT (41-43). But another clinical trial found that vitamin $\mathrm{D}$ treatment have no effects on VAT (44). In type 2 diabetes, Shab-Bidar et al. found that daily intake of vitamin D3-fortified doogh for $12 \mathrm{wk}$ improved the visceral fat accumulation (45). Vitamin D supplementation may be an effective means for preventing visceral fat accumulation and metabolic disorder in type 2 diabetes. The effect of vitamin D supplementation should be proved in type 2 diabetes by further study.

However, there are limitations to our study. First, the causality between visceral fat accumulation and vitamin D deficiency is debatable. In viscerally obese males, adipose tissue loss can increase the levels of $25(\mathrm{OH}) \mathrm{D}$ after 1-y lifestyle intervention (46). Vitamin D is a fat soluble hormone and is stored in adipose tissue. Volumetric dilution can partly explain the low vitamin D status of obesity (47). The decreased expression of the 25-hydroxylase in liver and subcutaneous adipose tissue could be another reason $(48,49)$. Because of the cross-sectional design of this study, we could not identify the causal relationship between visceral fat accumulation and vitamin D deficiency. Second, VAT were measured by bioelectrical impedance analysis in our study. Magnetic resonance imaging (MRI) and computed tomography (CT) are golden methods for evaluating visceral adipose tissue (50). The correlation between VFA measured by CT and measured by BIA did not display consistently on all studies. Some of them showed good correlations between VFA measured by CT and measured by BIA $(51,52)$. However, the correlation weakened with an advancing degree of obesity. The correlation coefficient reached 0.994 in males with BMI $<30 \mathrm{~kg} / \mathrm{m}^{2}$ and declined to 0.736 in males with BMI $\geqslant 30 \mathrm{~kg} / \mathrm{m}^{2}$ (26). In our study, 21 males (16.4\%) have BMI $\geqslant 30 \mathrm{~kg} / \mathrm{m}^{2}$. This might partly influence the outcome of our study. So we excluded subjects with BMI $\geqslant 30 \mathrm{~kg} / \mathrm{m}^{2}$ and analyzed again. Vitamin D insufficiency and vitamin D deficiency were still more likely to have visceral fat accumulation. But this difference was not statistically significant. This may be due to the decreased sample size. Third, insulin resistance is a potential confounding factor with visceral fat accumulation. Homeostasis model assessment of insulin resistance (HOMA-IR) is a major assessment of insulin resistance. However, insulin levels were not measured in our study. As we know, metabolic syndrome reflect the status of insulin resistance. In model 2 , the relationship between vitamin D status and visceral fat accumulation has not changed after adjusted MetS.

\section{CONCLUSION}

In summary, visceral fat accumulation linked to the cluster of cardiometabolic risk factor in males with type 
2 diabetes. There was a significant correlation between vitamin D deficiency and visceral fat accumulation. Further work will be necessary to confirm whether vitamin D supplementation can prevent visceral fat accumulation or lose weight can improve vitamin D status in type 2 diabetes.

\section{Authorship}

Research conception and design: FZY; experiments: DMF; statistical analysis of the data: BWL; writing of the manuscript: BWL.

\section{Disclosure of state of COI}

All authors declare that they have no conflict of interest.

\section{Funding \\ No funding.}

\section{Ethical approval}

All procedures performed in studies involving human participants were in accordance with the ethical standards of the institutional and/or national research committee and with the 1964 Helsinki declaration and its later amendments or comparable ethical standards.

\section{REFERENCES}

1) Wang C, Li J, Xue H, Li Y, Huang J, Mai J, Chen J, Cao J, Wu X, Guo D, Yu L, Gu D. 2015. Type 2 diabetes mellitus incidence in Chinese: contributions of overweight and obesity. Diabetes Res Clin Pract 107: 424-432.

2) Xue H, Wang C, Li Y, Chen J, Yu L, Liu X, Li J, Cao J, Deng Y, Guo D, Yang X, Huang J, Gu D. 2016. Incidence of type 2 diabetes and number of events attributable to abdominal obesity in China: A cohort study. J Diabetes $\mathbf{8}$ : 190-198.

3) Zhu W, Wu Y, Meng YF, Xing Q, Tao JJ, Lu J. 2018. Association of obesity and risk of diabetic retinopathy in diabetes patients: A meta-analysis of prospective cohort studies. Medicine (Baltimore) 97: e11807.

4) Man REK, Gan ATL, Fenwick EK, Gupta P, Wong MYZ, Wong TY, Tan GSW, Teo BW, Sabanayagam C, Lamoureux EL. 2018. The relationship between generalized and abdominal obesity with diabetic kidney disease in type 2 diabetes: A multiethnic Asian study and meta-analysis. Nutrients 10: 1685.

5) Bouchi R, Takeuchi T, Akihisa M, Ohara N, Nakano Y, Nishitani R, Murakami M, Fukuda T, Fujita M, Minami I, Izumiyama H, Hashimoto K, Yoshimoto T, Ogawa Y. 2015. High visceral fat with low subcutaneous fat accumulation as a determinant of atherosclerosis in patients with type 2 diabetes. Cardiovasc Diabetol 14: 136.

6) Smith JD, Borel AL, Nazare JA, Haffner SM, Balkau B, Ross R, Massien C, Almeras N, Despres JP. 2012. Visceral adipose tissue indicates the severity of cardiometabolic risk in patients with and without type 2 diabetes: results from the INSPIRE ME IAA study. J Clin Endocrinol Metab 97: 1517-1525.

7) Kurozumi A. Okada Y, Arao T, Tanaka Y. 2016. Excess visceral adipose tissue worsens the vascular endothelial function in patients with type 2 diabetes mellitus. Intern Med 55: 3091-3095.

8) Parva NR, Tadepalli S, Singh P, Qian A, Joshi R, Kandala
H, Nookala VK, Cheriyath P. 2018. Prevalence of vitamin D deficiency and associated risk factors in the US population (2011-2012). Cureus 10: e2741.

9) Yu S, Fang H, Han J, Cheng X, Xia L, Li S, Liu M, Tao Z, Wang L, Hou L, Qin X, Li P, Zhang R, Su W, Qiu L. 2015. The high prevalence of hypovitaminosis D in China: a multicenter vitamin D status survey. Medicine 94: e585.

10) Agmon-Levin N, Theodor E, Segal RM, Shoenfeld Y. 2013. Vitamin D in systemic and organ-specific autoimmune diseases. Clin Rev Allergy Immunol 45: 256-266.

11) Feldman D, Krishnan AV, Swami S, Giovannucci E, Feldman BJ. 2014. The role of vitamin D in reducing cancer risk and progression. Nat Rev Cancer 14: 342-357.

12) Lerner PP, Sharony L, Miodownik C. 2018. Association between mental disorders, cognitive disturbances and vitamin D serum level: Current state. Clin Nutr ESPEN 23: 89-102.

13) Norman PE, Powell JT. 2014. Vitamin D and cardiovascular disease. Circ Res 114: 379-393.

14) Rafiq S, Jeppesen PB. 2018. Body mass index, vitamin D, and type 2 diabetes: A systematic review and meta-analysis. Nutrients 10: 1182.

15) Mansouri M, Miri A, Varmaghani M, Abbasi R, Taha P, Ramezani S, Rahmani E, Armaghan R, Sadeghi O. 2019. Vitamin D deficiency in relation to general and abdominal obesity among high educated adults. Eat Weight Disord 24: 83-90.

16) Zhang M, Li P, Zhu Y, Chang H, Wang X, Liu W, Zhang Y, Huang G. 2015. Higher visceral fat area increases the risk of vitamin D insufficiency and deficiency in Chinese adults. Nutr Metab (Lond) 12: 50.

17) Hannemann A, Thuesen BH, Friedrich N, Volzke H, Steveling A, Ittermann T, Hegenscheid K, Nauck M, Linneberg A, Wallaschofski H. 2015. Adiposity measures and vitamin D concentrations in Northeast Germany and Denmark. Nutr Metab (Lond) 12: 24.

18) Hao Y, Ma X, Shen Y, Ni J, Luo Y, Xiao Y, Bao Y, Jia W. 2014. Associations of serum 25-hydroxyvitamin D3 levels with visceral adipose tissue in Chinese men with normal glucose tolerance. PLoS One 9: e86773.

19) Taheri E, Saedisomeolia A, Djalali M, Qorbani M, Madani Civi M. 2012. The relationship between serum 25-hydroxy vitamin D concentration and obesity in type 2 diabetic patients and healthy subjects. J Diabetes Metab Disord 11: 16.

20) Kocot J, Dziemidok P, Kielczykowska M, Kurzepa J, Szczesniak G, Musik I. 2017. Is there any relationship between plasma 25-hydroxyvitamin $\mathrm{D}(3)$, adipokine profiles and excessive body weight in type 2 diabetic patients? Int J Environ Res Public Health 15: 19.

21) American Diabetes Association. 2014. Diagnosis and classification of diabetes mellitus. Diabetes Care $\mathbf{3 7}$ (Suppl 1): S81-S90.

22) Xu Q, Li X, Gao B, Xu Y, Wang Y, Zhang N, Bond Lau W, Zhou J, Ji Q. 2013. Comparative performance of four equations estimating glomerular filtration rate in adult Chinese diabetics. J Endocrinol Invest 36: 293-297.

23) Chinese Diabetes Society. 2014. Chinese guideline for type 2 diabetes. Chin J Endocrinol Metab 30: 893-942.

24) Aspray TJ, Bowring C, Fraser W, Gittoes N, Javaid MK, Macdonald H, Patel S, Selby P, Tanna N, Francis RM, National Osteoporosis Society. 2014. National Osteoporosis Society vitamin D guideline summary. Age Ageing 43: 592-595.

25) Examination Committee of Criteria for 'Obesity Disease' 
in Japan, Japan Society for the Study of O. 2002. New criteria for 'obesity disease' in Japan. Circ J 66: 987-992.

26) Berker D, Koparal S, Isik S, Pasaoglu L, Aydin Y, Erol K, Delibasi T, Guler S. 2010. Compatibility of different methods for the measurement of visceral fat in different body mass index strata. Diagn Interv Radiol 16: 99-105.

27) Ma CM, Lu N, Wang R, Liu XL, Lu Q, Yin FZ. 2017. Three novel obese indicators perform better in monitoring management of metabolic syndrome in type 2 diabetes. Sci Rep 7: 9843.

28) Fox CS, Massaro JM, Hoffmann U, Pou KM, Maurovich-Horvat P, Liu CY, Vasan RS, Murabito JM, Meigs JB, Cupples LA, D'Agostino RB Sr, O’Donnell CJ. 2007. Abdominal visceral and subcutaneous adipose tissue compartments: association with metabolic risk factors in the Framingham Heart Study. Circulation 116: 39-48.

29) Wang C, Wang X, Tian H, Fang F, Han X. 2014. Association of abdominal fat distribution by computed tomography with body mass index and metabolic syndrome in Chinese elders. Zhonghua Yi Xue Za Zhi 94: 908-912.

30) He HB, Zhao ZG, Pu YF, Chen J, Ni YX, Zhong J, Liu HY, Li YS, Yan ZC, Liu DY, Zhu ZM. 2008. Relationship of different types of abdominal obesity to risk of metabolic syndrome. Zhonghua Yi Xue Za Zhi 88: 1251-1254.

31) Matsushita Y, Nakagawa T, Yamamoto S, Takahashi Y, Yokoyama T, Mizoue T, Noda M. 2012. Effect of longitudinal changes in visceral fat area and other anthropometric indices to the changes in metabolic risk factors in Japanese men: the Hitachi health study. Diabetes Care 35: 1139-1143.

32) Matsushita Y, Nakagawa T, Yamamoto S, Takahashi Y, Yokoyama T, Mizoue T, Noda M. 2013. Effect of longitudinal changes in visceral fat area on incidence of metabolic risk factors: the Hitachi health study. Obesity (Silver Spring) 21: 2126-2129.

33) Schorr M, Dichtel LE, Gerweck AV, Valera RD, Torriani M, Miller KK, Bredella MA. 2018. Sex differences in body composition and association with cardiometabolic risk. Biol Sex Differ 9: 28.

34) Marin P, Andersson B, Ottosson M, Olbe L, Chowdhury B, Kvist H, Holm G, Sjostrom L, Bjorntorp P. 1992. The morphology and metabolism of intraabdominal adipose tissue in men. Metabolism 41: 1242-1248.

35) Item F, Konrad D. 2012. Visceral fat and metabolic inflammation: the portal theory revisited. Obes Rev 13 (Suppl 2): 30-39.

36) Tu AW, Humphries KH, Lear SA. 2017. Longitudinal changes in visceral and subcutaneous adipose tissue and metabolic syndrome: Results from the Multicultural Community Health Assessment Trial (M-CHAT). Diabetes Metab Syndr 11 (Suppl 2): S957-S961.

37) Cheng S, Massaro JM, Fox CS, Larson MG, Keyes MJ, McCabe EL, Robins SJ, O'Donnell CJ, Hoffmann U, Jacques PF, Booth SL, Vasan RS, Wolf M, Wang TJ. 2010. Adiposity, cardiometabolic risk, and vitamin D status: the Framingham Heart Study. Diabetes 59: 242248.

38) Kong J, Li YC. 2006. Molecular mechanism of 1,25-dihydroxyvitamin D3 inhibition of adipogenesis in 3T3-L1 cells. Am J Physiol Endocrinol Metab 290: E916E924.

39) Felicidade I, Sartori D, Coort SLM, Semprebon SC, Niwa AM, D’Epiro GFR, Biazi BI, Marques LA, Evelo CT, Mantovani MS, Ribeiro LR. 2018. Role of 1alpha,25-dihy- droxyvitamin D3 in adipogenesis of SGBS cells: New insights into human preadipocyte proliferation. Cell Physiol Biochem 48: 397-408.

40) Autier P, Mullie P, Macacu A, Dragomir M, Boniol M, Coppens K, Pizot C, Boniol M. 2017. Effect of vitamin D supplementation on non-skeletal disorders: a systematic review of meta-analyses and randomised trials. Lancet Diabetes Endocrinol 5: 986-1004.

41) Rosenblum JL, Castro VM, Moore CE, Kaplan LM. 2012. Calcium and vitamin D supplementation is associated with decreased abdominal visceral adipose tissue in overweight and obese adults. Am J Clin Nutr 95: 101108.

42) Zhu W, Cai D, Wang Y, Lin N, Hu Q, Qi Y, Ma S, Amarasekara S. 2013. Calcium plus vitamin D3 supplementation facilitated fat loss in overweight and obese college students with very-low calcium consumption: a randomized controlled trial. Nutr J 12: 8.

43) Nikooyeh B, Neyestani TR, Zahedirad M, Mohammadi M, Hosseini SH, Abdollahi Z, Salehi F, Mirzay Razaz J, Shariatzadeh N, Kalayi A, Lotfollahi N, Maleki MR. 2016. Vitamin D-fortified bread is as effective as supplement in improving vitamin D status: A randomized clinical trial. J Clin Endocrinol Metab 101: 2511-2519.

44) Wamberg L, Kampmann U, Stodkilde-Jorgensen H, Rejnmark L, Pedersen SB, Richelsen B. 2013. Effects of vitamin D supplementation on body fat accumulation, inflammation, and metabolic risk factors in obese adults with low vitamin D levels-results from a randomized trial. Eur J Intern Med 24: 644-649.

45) Shab-Bidar S, Neyestani TR, Djazayery A. 2015. Vitamin D receptor Cdx-2-dependent response of central obesity to vitamin $\mathrm{D}$ intake in the subjects with type 2 diabetes: a randomised clinical trial. Br I Nutr 114: 1375-1384.

46) Gangloff A, Bergeron J, Pelletier-Beaumont E, Nazare JA, Smith J, Borel AL, Lemieux I, Tremblay A, Poirier P, Almeras N, Despres JP. 2015. Effect of adipose tissue volume loss on circulating 25-hydroxyvitamin D levels: results from a 1-year lifestyle intervention in viscerally obese men. Int J Obes (Lond) 39: 1638-1643.

47) Drincic AT, Armas LA, Van Diest EE, Heaney RP. 2012. Volumetric dilution, rather than sequestration best explains the low vitamin D status of obesity. Obesity (Silver Spring) 20: 1444-1448.

48) Park JM, Park CY, Han SN. 2015. High fat diet-induced obesity alters vitamin D metabolizing enzyme expression in mice. Biofactors 41: 175-182.

49) Wamberg L, Christiansen T, Paulsen SK, Fisker S, Rask P, Rejnmark L, Richelsen B, Pedersen SB. 2013. Expression of vitamin D-metabolizing enzymes in human adipose tissue - the effect of obesity and diet-induced weight loss. Int J Obes (Lond) 37: 651-657.

50) Fang H, Berg E, Cheng X, Shen W. 2018. How to best assess abdominal obesity. Curr Opin Clin Nutr Metab Care 21: 360-365.

51) Ryo M, Maeda K, Onda T, Katashima M, Okumiya A, Nishida M, Yamaguchi T, Funahashi T, Matsuzawa Y, Nakamura T, Shimomura I. 2005. A new simple method for the measurement of visceral fat accumulation by bioelectrical impedance. Diabetes Care 28: 451-453.

52) Demura S, Sato S. 2007. Prediction of visceral fat area at the umbilicus level using fat mass of the trunk: The validity of bioelectrical impedance analysis. J Sports Sci 25: 823-833. 